\title{
Pengendalian Lampu Lalu Lintas Cerdas di Persimpangan Empat Ruas yang Kompleks Menggunakan Algoritma Adaptive Neuro Fuzzy Inference System
}

\author{
Budy Santoso ${ }^{\# 1}$, Azminuddin I. S. Azis ${ }^{\# 2}$, Andi Bode ${ }^{\# 3}$ \\ \#Program Studi Teknik Informatika, Fakultas Ilmu Komputer, Universitas Ichsan Gorontalo \\ Jl. Raden Saleh No. 17, Telp. (0435) 829975, Fax (0435) 829976, Gorontalo \\ budysantoso@unisan.ac.id \\ 2azminuddinaziseunisan.ac.id \\ 3bodeandijreunisan.ac.id
}

\begin{abstract}
Abstrak - Masalah transportasi masih sering dihadapkan pada fenomena kemacetan arus lalu lintas yang berdampak pada kecelakaan lalu lintas, polusi, dan kerugian ekonomi. Salah satu cara untuk meminimalisir fenomena tersebut melalui pengendalian sistem lampu lalu lintas yang baik terhadap arus lalu lintas jangka pendek di persimpangan jalan. Pengendalian lampu lalu lintas secara statis terbukti belum optimal dalam meminimalisir kemacetan arus lalu lintas, salah satu penyebabnya karena kondisi arus lalu lintas yang bervariasi sehingga tidak mudah diprediksi. Fuzzy Inference System (FIS) sering terbukti mampu menunjukkan hasil yang lebih baik daripada pengendalian lampu lalu lintas secara statis. Namun FIS tidak dapat diterapkan pada kondisi arus lalu lintas yang bervariasi atau di persimpangan jalan yang berbeda karena metode tersebut tidak mampu mempelajari kondisi arus lalu lintas secara real time. Agar FIS mampu melakukan pembelajaran, maka pendekatan machine learning dapat diterapkan pada FIS. Salah satu pengembangannya adalah Adaptive Neuro Fuzzy Inference System (ANFIS) yang dapat mengendalikan lampu lalu lintas cerdas secara dinamis dengan hasil yang lebih baik daripada FIS. Namun umumnya ANFIS diuji coba pada persimpangan jalan yang normal. Bagaimana jika di persimpangan yang kompleks? Persimpangan yang memiliki beberapa ruas/jalur utama yang besar (jalur poros), sementara ruas laiinya kecil, bahkan terdapat ruas yang tidak berpotongan, sehingga ada prioritas untuk setiap ruasnya. Hasilnya, penerapan ANFIS (3 Gauss Mf) untuk pengendalian lampu lalu lintas cerdas/dinamis di persimpangan empat ruas yang kompleks mampu mereduksi Average Waiting Times (AWT) rata-rata sebesar 3,4071E-05 detik dengan 2,7156 RMSE rata-rata, menggunakan variabel Queues Quantity dan Priority Degree. Sedangkan jika menggunakan variabel Arrival Times, Transportation Type, dan Goal Junction, ANFIS (4 TrapMf) mampu mereduksi AWT sebesar 0,0779 detik dengan 19,7646 RMSE.
\end{abstract}

Kata kunci- ANFIS, Pengendalian Lampu Lalu Lintas Cerdas, Persimpangan Empat Ruas yang Kompleks.

\section{Pendahuluan}

Masalah transportasi masih sering dihadapkan pada fenomena kemacetan arus lalu lintas yang berdampak pada kecelakaan lalu lintas, polusi, dan kerugian ekonomi [1][5]. Salah satu cara untuk meminimalisir fenomena tersebut melalui manajemen yang baik terhadap arus lalu lintas di persimpangan jalan. Arus lalu lintas jangka pendek di persimpangan jalan dapat dikendalikan dengan sistem lampu lalu lintas, secara statis maupun dinamis [2], [6], [7]. Namun pengendalian lampu lalu lintas secara statis terbukti belum optimal dalam meminimalisir kemacetan arus lalu lintas karena meningkatnya jumlah kendaraan secara eksponensial yang tidak sejalan dengan perkembangan kapasitas jalan [3], [4], [8], [9] sehingga kondisi arus lalu lintas tidak mudah ditebak (bervariasi) [6]. Oleh karena itu, pengendalian lampu lalu lintas cerdas/dinamis harus terus ditingkatkan.

Pendekatan soft computing maupun machine learning sering digunakan untuk mengatasi masalah tersebut [2], [10], [11], umumnya menggunakan metode Fuzzy Inference System (FIS) (ditunjukkan pada Tabel I) dengan hasil yang lebih baik daripada pengendalian lampu lalu lintas secara statis. Namun FIS tidak dapat diterapkan pada kondisi arus lalu lintas yang bervariasi atau dipersimpangan jalan yang berbeda karena metode tersebut tidak mampu mempelajari kondisi arus lalu lintas secara real time [6], [12], [13]. Sementara itu, pendekatan machine learning mampu memberikan pengetahuan melalui pembelajarannya [14]-[16]. Dengan demikian, Agar FIS mampu melakukan pembelajaran, maka pendekatan machine learning dapat diterapkan pada FIS. Salah satu pengembangannya adalah Adaptive Neuro Fuzzy Inference System (ANFIS) yang dapat mengendalikan lampu lalu lintas cerdas secara dinamis dengan hasil yang lebih baik daripada FIS maupun Artificial Neural Network 
(ANN), yaitu dengan akurasi $=95 \%$ dan Average Waiting Time $(\mathrm{AWT})=2,186$ menit di persimpangan 4 ruas [13], mampu mereduksi AWT sebesar 20,24\% di persimpangan 6 ruas [6], maupun $40 \%$ di persimpangan 4 ruas [17], bahkan $100 \%$ akurat dalam memprediksi arus lalu lintas dan kebisingannya [18]. Secara lengkap, penerapan pendekatan soft computing dan machine learning untuk Traffic Light Control (TLC) di tunjukkan pada Tabel I.

TABEL I

PENERAPAN SOFT COMPUTING DAN MACHINE LEARNING UNTUK TLC

\begin{tabular}{|c|c|c|c|}
\hline Year, Ref & Methods & Junctions & Results \\
\hline $2001,[13]$ & Fuzzy-ANN & 4 & $\mathrm{AWT}=2,186$ \\
\hline 2004, [19] & Multi Agent & 4 & Tools \\
\hline $2006,[20]$ & SPSA-NN & Multi & AWT reduction \\
\hline $2006,[21]$ & Fuzzy & 4 & Tools \\
\hline $2007,[22]$ & WSN - ICAs & Multi & AWT reduction \\
\hline $2007,[23]$ & Multi Agent & Multi & AWT reduction \\
\hline $2008,[24]$ & DATLCES & $4 \times 3 \times 6$ & AWT reduction \\
\hline $2008,[25]$ & Multi Agent & 18 & Prototype \\
\hline $2008,[26]$ & Fuzzy & 4 & Simulation \\
\hline $2008,[27]$ & Fuzzy & 4 & Prototype \\
\hline $2008,[28]$ & Fuzzy & 4 & Prototype \\
\hline $2008,[29]$ & Fuzzy- & Multi & $\mathrm{MRSE}=3.878 \%$ \\
\hline $2009,[30]$ & Genetic & 4 & Simulation \\
\hline $2010,[31]$ & Fuzzy & Multi & AWT reduction \\
\hline $2010,[32]$ & ADP & 4 & AWT reduction \\
\hline $2010,[33]$ & Fuzzy & 4 & AWT reduction \\
\hline $2010,[34]$ & Fuzzy & Multi & AWT reduction \\
\hline $2011,[8]$ & Multi Agent & 4 & AWT reduction \\
\hline 2011, [6] & Fuzzy & 6 & AWT reduction \\
\hline $2011,[35]$ & ANFIS & Multi & AWT reduction \\
\hline $2012,[36]$ & Multi Agent & 4 & AWT reduction \\
\hline $2013,[37]$ & TAPIOCA & $4 \& 4 \times 4$ & Speed increase \\
\hline $2013,[38]$ & DA & 4 & $2.54 \%$ dari $\mathrm{ANN}$ \\
\hline $2013,[39]$ & ANN- & Multi & K-Means \& HC \\
\hline $2013,[40]$ & Genetic & Multi & NVRD \& OJT \\
\hline $2013,[41]$ & HC-K-Means & 4 & AWT reduction \\
\hline $2013,[7]$ & PSO & 8 & AWT reduction \\
\hline $2014,[1]$ & QL \& ANN & 3 & Queues reduction \\
\hline $2014,[42]$ & VANET & $?$ & Error $=0.1$ \\
\hline $2015,[43]$ & $\mathrm{DP}$ & Multi & AWT reduction \\
\hline $2015,[44]$ & ANN & $4 \times 4$ & AWT reduction \\
\hline $2015,[45]$ & ITLC & 4 & Confidence $=95 \%$ \\
\hline $2015,[46]$ & Fuzzy-WSN & 4 & Error $<4 \%$ \\
\hline $2016,[47]$ & DT3P & $?$ & AWT reduction \\
\hline 2016, [9] & FCM-PSO- & Multi & Congestion reduction \\
\hline $2016,[4]$ & SVR & Multi & 2 level control \\
\hline $2016,[5]$ & Fuzzy & 4 & AWT reduction \\
\hline $2016,[18]$ & Pheromone & Multi & $100 \%$ Accuracy \\
\hline $2017,[48]$ & 2 Level TLC & 4 & AWT reduction \\
\hline $2017,[49]$ & Fuzzy & 4 & Simulation \\
\hline $2017,[50]$ & ANFIS & Multi & AWT reduction \\
\hline $2017,[51]$ & EDTLC & 4 & AWT reduction \\
\hline $2017,[52]$ & Fuzzy & Multi & Simulation \\
\hline $2017,[17]$ & Multi Agent & 4 & AWT reduction \\
\hline $2017,[53]$ & $\mathrm{HNN}-$ & 4 & AWT reduction \\
\hline $2017,[54]$ & Genetic & 3 & Queues reduction \\
\hline $2017,[12]$ & Round Robin & 4 & $\mathrm{AWT}=2,98$ \\
\hline $2018,[55]$ & ANFIS & 4 & AWT reduction \\
\hline $2018,[56]$ & DHP-HCP & 4 & AWT reduction \\
\hline $2018,[57]$ & Fuzzy & TaxiBJ & $\mathrm{RMSE}=0.3336$ \\
\hline $2018,[58]$ & $\begin{array}{l}\text { Fuzzy } \\
\text { Intellight } \\
\text { Fuzzy } \\
\text { DL-Fuzzy } \\
\text { Multi Agent }\end{array}$ & Multi & AWT reduction \\
\hline
\end{tabular}

Namun demikian, umunya ANFIS diuji coba pada persimpangan jalan yang normal. Bagaimana jika dipersimpangan yang kompleks? Persimpangan yang memiliki beberapa ruas/jalur utama yang besar (jalur poros), sementara ruas laiinya kecil, bahkan terdapat ruas yang tidak berpotongan, sehingga ada prioritas untuk setiap ruasnya. Persimpangan yang kompleks seperti itu tentunya membutuhkan pengendalian lampu lalu lintas yang lebih kompleks pula. Salah satu persimpangan yang kompleks seperti itu terdapat di Gotontalo (Gambar 1). Observasi sementara kami menunjukkan bahwa durasi lampu lalu lintas secara statis di lokasi tersebut tidak efisien karena sangat sering menimbulkan antrian yang panjang, bahkan kemacetan arus lalu lintas yang terjadi di pusat persimpangan, hingga kadang berujung pada pelanggaran rambu lampu lalu lintas oleh pengemudi.

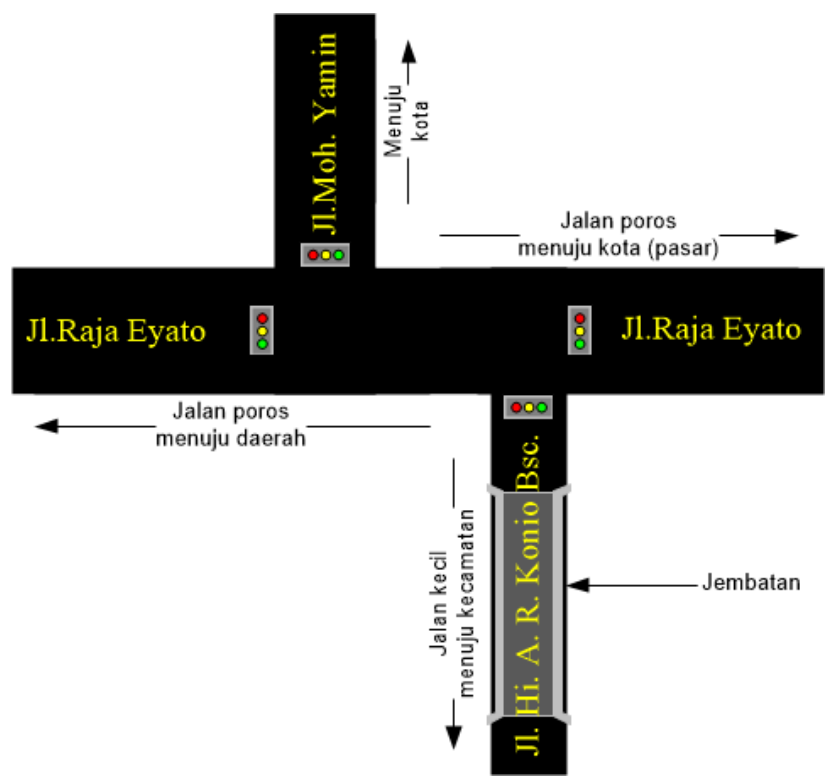

Gambar. 1 Persimpangan empat ruas yang kompleks

Bagaimana jika anda mengantri dengan waktu yang cukup lama karena terjadi kemacetan arus lalu lintas yang dikendalikan dengan lampu lalu lintas statis di suatu persimpangan jalan yang kompleks seperti pada Gambar 1? Bagaimana jika kemacetan tersebut berdampak terhadap pelanggaran lalu lintas, kecelakaan lalu lintas, polusi, dan bahkan kerugian ekonomi? Oleh karena itu, pengendalian lampu lalu lintas cerdas secara dinamis yang merupakan salah satu bagian dari pengembangan Intelligent Transportation System (ITS) harus terus ditingkatkan.

Dengan menggunakan teknik observasi, dua dataset dikumpulkan dari persimpangan tersebut (Gambar 1). Struktur dataset pertama (D1) mengacu pada penelitian yang dilakukan oleh R. Hawi, G. Okeyo, \& M. Kimwele dalam penelitiannya tentang pengendalian lampu lalu lintas cerdas menggunakan FIS dan Wireless Sensor Network (WSN), pada tahun 2017 [12]. Sedangkan struktur dataset kedua (D2), dengan sedikit modifikasi pada variabel yang digunakan, mengacu pada penelitian yang dilakukan oleh B. S. Putra, R. S. Wahono, \& R. I. Akbar dalam 
penelitiannya tentang pengendalian lampu lalu lintas cerdas enam ruas menggunakan ANFIS, pada tahun 2011 [6]. Secara rinci, struktur kedua dataset tersebut ditunjukkan pada Tabel II berikut ini.

TABEL II

STRUKTUR DATASET

\begin{tabular}{lllll}
\hline Kode & Variabel & Tipe & Jenis & Satuan \\
\hline D1 & QQ & Integer & Input & Kendaraan \\
& WT & Integer & Input/Output & Detik \\
& PD & Real & Input/Output & $1,000-10,000$ \\
& GT & Integer & Input Simulasi & $($ QQ*WT $) / 6$ \\
D2 & AT & Integer & Input & Detik \\
& TT & Ordinal & Input & {$[2 ; 4 ; 7 ; 10]$} \\
& GJ & Ordinal & Input & {$[1 ; 2 ; 3]$} \\
& WT & Integer & Output & Detik \\
\hline
\end{tabular}

Dataset D1 merupakan data akumulasi arus lalu lintas dalam setiap periode lampu lalu lintas. Setiap variabel pada D1 terdapat pada setiap ruas pada Gambar 1 yang terdiri dari Ruas A (bawah), Ruas B (kiri), Ruas C (atas), dan Ruas D (kanan). Sedangkan dataset D2 merupakan data per kendaraan. Variabel-variabel pada D2 mewakili keempat ruas pada Gambar 1 .

Variabel-variabel yang digunakan pada D1 terdiri dari Queues Quantity (QQ), Waiting Times (WT), Priority Degree (PD), dan Green Light Times (GT). QQ berfungsi sebagai variabel input, merupakan jumlah antrian kendaraan dalam suatu periode lampu merah pada suatu ruas. WT merupakan waktu tunggu semua kendaraan pada suatu ruas dalam satuan detik. Awalnya WT berfungsi sebagai salah satu variabel input yang nilainya terdiri dari $0,20,40$, dan 60 detik karena durasi lampu hijau $=20$ detik untuk memperoleh output PD menggunakan FIS. Selanjutnya WT berfungsi sebagai variabel output menggunakan ANFIS. PD berfungsi sebagai variabel output yang nilainya diperoleh dengan menggunakan FIS, merupakan tingkat prioritas suatu ruas untuk lampu hijau menyala, di mana ruas yang memiliki PD tertinggi yang memperoleh lampu hijau, sehingga bersifat dinamis (lampu hijau tidak bergiliran). GT berfungsi sebagai variabel output namun hanya pada/untuk simulasi, merupakan durasi lampu hijau pada suatu ruas dalam satuan detik, di mana nilainya diperoleh menggunakan Persamaan (1) yang diusulkan oleh R. Hawi, G. Okeyo, \& M. Kimwele dalam penelitiannya pada tahun 2017 [12], dengan sedikit modifikasi atas pertimbangan lokasi.

$$
\mathrm{GT}=\frac{\mathrm{QQ} * \mathrm{WT}}{6}
$$

Variabel-variabel yang digunakan pada D2 terdiri dari Arrival Times (AT), Transportation Type (TT), Goal Junction (GT), dan Waiting Times (WT). AT berfungsi sebagai variabel input, merupakan waktu kendaraan tiba di suatu ruas dalam satuan detik yang nilainya adalah detik ke berapa kendaraan tiba di suatu ruas lampu merah $(0-20$ detik). TT berfungsi sebagai variabel input, merupakan tipe kendaraan yang dikategorikan menjadi 4 nilai ordinal, yaitu 2 (kendaraan roda $2-3$ ), 4 (kendaraan roda 4 ), 7 (kendaraan roda $6-8$ ), dan 10 (kendaraan dengan roda $>=$
10). GJ berfungsi sebagai variabel input, merupakan jarak dari ruas asal ke ruas tujuan suatu kendaraan yang dikategorikan menjadi 3 nilai ordinal, yaitu 1 (ke ruas dekat), 2 (ke ruas sedang), dan 3 (ke ruas jauh). WT pada D2 berfungsi sebagai variabel output, merupakan waktu tunggu suatu kendaraan pada suatu ruas (waktu kendaraan tiba di ruas asal hingga sampai di ruas tujuan) dalam satuan detik.

Berdasarkan latar belakang yang telah dikemukakan sebelumnya, maka penelitian ini bertujuan untuk menguji coba metode ANFIS dalam mengendalikan lampu lalu lintas cerdas secara dinamis di persimpangan empat ruas yang kompleks, sehingga dapat mereduksi AWT kendaraan dengan error estimation yang kecil di persimpangan tersebut. Kedepannya, diharapkan model yang diusulkan ini dapat diimplementasikan pada sistem lampu lalu lintas cerdas di persimpangan-persimpangan 4 ruas yang kompleks, sehingga dapat berdampak dalam mereduksi pelanggaran lalu lintas, kecelakaan lalu lintas, polusi, dan bahkan kerugian ekonomi yang disebabkan kemacetan arus lalu lintas.

\section{METODE}

Penelitian ini merupakan penelitian eksperimental. Dipandang dari jenis informasi yang diolah, maka penelitian ini merupakan penelitian kuantitatif. Dipandang dari perlakuan terhadap data, maka penelitian ini merupakan penelitian konfirmatori. Soft computing, machine learning, dan Intelligent Transportation System merupakan subjek-subjek penelitian ini. Sedangkan objek penelitian ini adalah lampu lalu lintas di persimpangan empat ruas yang kompleks. Penelitian ini dilaksanakan selama satu tahun lebih, dari April 2018 hingga Oktober 2019.

Model eksperimen yang dilakukan dalam penelitian ini terdiri dari empat percobaan. Eksperimen pertama (E1) merupakan pemodelan FIS untuk memberikan nilai PD pada data input di dataset D1. Eksperimen kedua (E2) merupakan pemodelan ANFIS dengan mengunakan data input dan output di dataset D1 yang diperoleh dari eksperimen E1 untuk menghasikan output WT. Eksperimen ketiga (E3) merupakan pemodelan ANFIS dengan menggunakan data input dan output di dataset D2 untuk menghasilkan output WT. Eksperimen terakhir adalah simulasi (E4) yang merupakan model simulasi dari ANFIS menggunakan data input di dataset D1 dengan strategi yang sama seperti ekperimen E1. Secara rinci, percobaan-percobaan tersebut ditunjukkan pada Tabel III berikut ini. Sedangkan alat bantu yang digunakan dalam melakukan eksperimen/pemodelan terhadap metode yang diusulkan (Gambar 2) yaitu Matlab.

TABEL III

MODEL EKSPERIMEN

\begin{tabular}{llllll}
\hline Kode & DS & Input & Output & Metode & Evaluasi \\
\hline E1 & D1 & QQ, WT & PD & FIS & - \\
E2 & D1 & QQ, PD & WT & ANFIS & RMSE \& AWT \\
E3 & D2 & AT, TT, GJ & Wt & ANFIS & RMSE \& AWT \\
E4 & D1 & QQ, WT & PD, GT & ANFIS & - \\
\hline
\end{tabular}




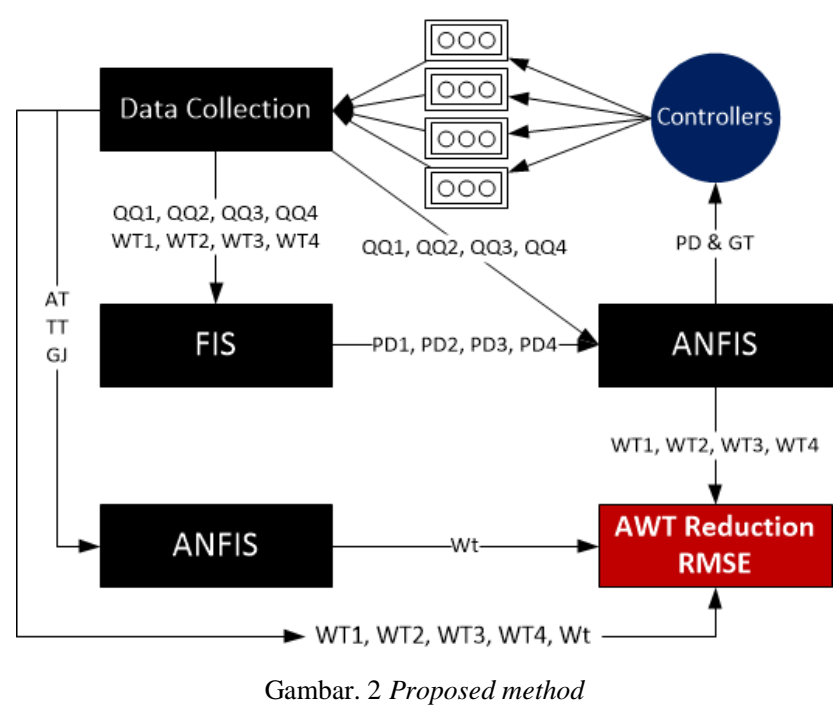

\section{A. Data Collection}

Prosedur pertama yang dilakukan adalah pengumpulan data menggunakan teknik observasi. Pengumpulan data dilakukan pada jam 06:30 AM - 08:30 AM (pagi), 10:00 AM - 11:30 AM (siang), 02:00 PM - 05:30 PM (siang/sore), dan 07:00 PM - 10:00 PM (malam) selama 1 minggu. Pengumpulan data dilakukan secara manual, baik di waktu arus lalu lintas dalam keadaan macet, seperti di pagi dan siang hari, maupun tidak macet.

\section{B. Fuzzy Inference System (FIS)}

Fuzzy Inference System (FIS) atau biasa disebut Fuzzy Logic memiliki kemampuan dalam menalar, toleransi terhadap data-data yang tidak tepat, mampu memodelkan fungsi-fungsi nonlinear yang kompleks, dan mampu mengaplikasikan pengalaman pakar tanpa melalui proses pelatihan [59]. Proses FIS terdiri dari Fuzzification, Knowledge Base, Machine Inference, dan Defuzzification. Lebih jelasnya, proses FIS ditunjukkan pada Gambar 3 berikut ini.

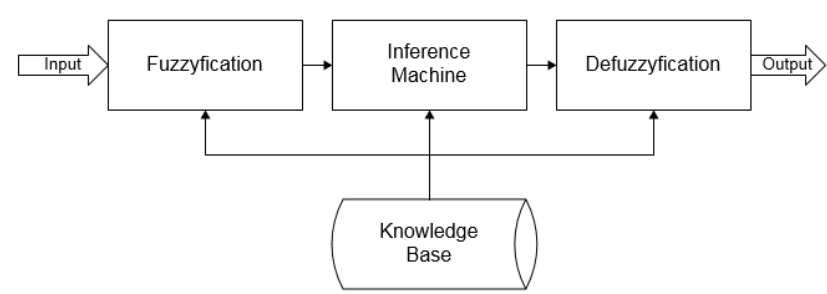

Gambar. 3 Proses FIS

Knowledge Base merupakan kumpulan aturan-aturan dalam bentuk pernyataan "If ... Then" yang umumnya berasal dari pengetahuan pakar. Fuzzification merupakan proses untuk mengubah inputan menjadi variabel linguistik menggunakan fungsi keanggotaan. Inference Machine merupakan proses untuk menalar inputan menjadi output dengan mengikuti aturan-aturan yang telah ditetapkan pada Knowledge Base. Defuzzification merupakan proses untuk mengubah output Fuzzy yang diperoleh dari Inference Machine menjadi nilai tegas menggunakan fungsi keanggotaan yang sesuai pada proses fuzzyfication sebelumnya.

Nilai PD dari setiap data yang ada di dataset D1 ditentukan menggunakan FIS. Fungsi keanggotaan yang digunakan yaitu Triangular MF (TriMF), ditunjukkan pada Gambar 4 untuk fungsi keanggotaan QQ, Gambar 5 untuk fungsi keanggotaan WT, dan Gambar 6 untuk fungsi keanggotaan PD sebagai output. Pendekatan ini diadopsi dari penelitian yang dilakukan oleh R. Hawi, G. Okeyo, \& M. Kimwele dalam penelitiannya tentang pengendalian lampu lalu lintas cerdas menggunakan FIS dan Wireless Sensor Network (WSN), pada tahun 2017 [12], dengan sedikit modifikasi pada range membership atas pertimbangan lokasi.

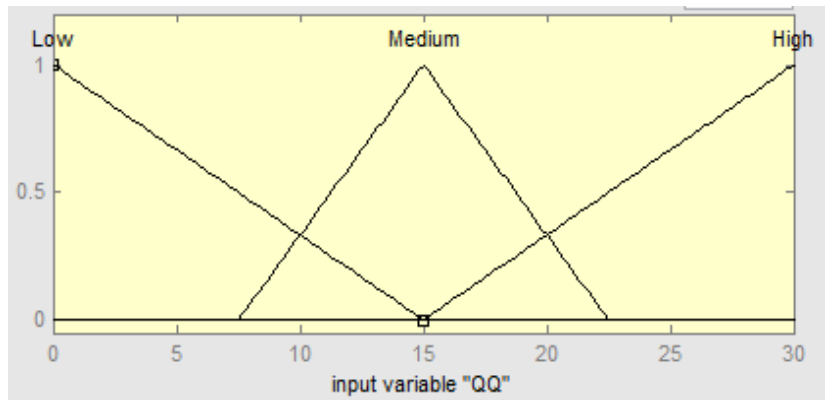

Gambar. 4 Fungsi keanggotaan input QQ

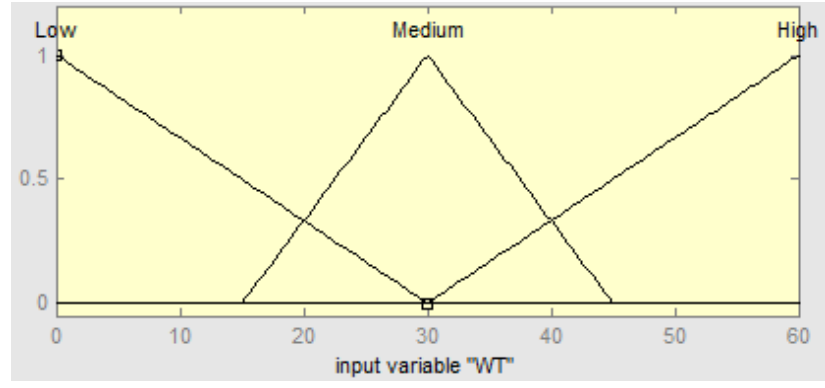

Gambar. 5 Fungsi keanggotaan input WT

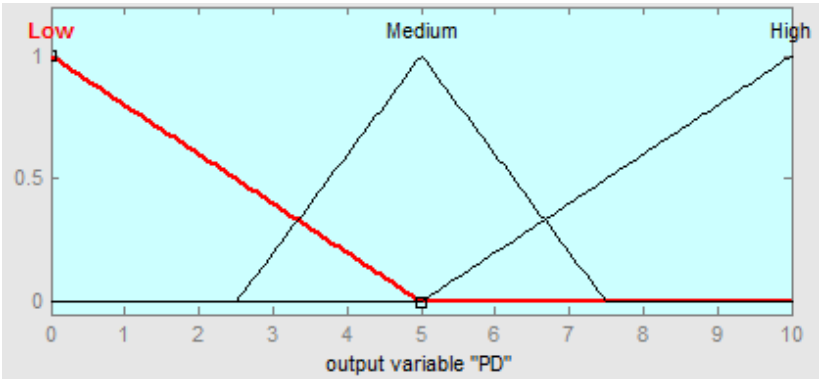

Gambar. 6 Fungsi keanggotaan output PD

Algoritma FIS yang digunakan adalah Fuzzy Mamdani dengan parameter Defuzzification yang digunakan adalah 'mom', dengan 9 rule sebagai berikut [12]:

- If QQ Low and WT Low Then PD Low

- If QQ Low and WT Medium Then PD Low

- If QQ Low and WT High Then PD Medium

- If QQ Medium and WT Low Then PD Low

- If QQ Medium and WT Medium Then PD Medium

- If QQ Medium and WT High Then PD High 
- If QQ High and WT Low Then PD Medium

- If QQ High and WT Medium Then PD High

- If QQ High and WT High Then PD High

\section{Adaptive Neuro Fuzzy Inference System (ANFIS)}

Pada prinsipnya, FIS tidak mampu melakukan pembelajaran sendiri, maka dengan menerapkan pendekatan machine learning, FIS akan dapat melakukan pendekatan reasoning dan learning. Salah satu hasil dari pengembangan pendekatan ini adalah Adaptive Neuro Fuzzy Inference System (ANFIS), di mana Artificial Neural Network $(A N N)$ bertugas untuk melakukan learning berdasarkan data latih untuk mengoptimalkan prosesproses FIS dalam melakukan reasoning, sehingga algoritma ini menjadi dinamis. Lebih jelasnya, proses ANFIS ditunjukkan pada Gambar 4, di mana arsitektur jaringan ANN pada ANFIS untuk eksperimen E2 dan E3 ditunjukkan pada Gambar 5 dan Gambar 6.

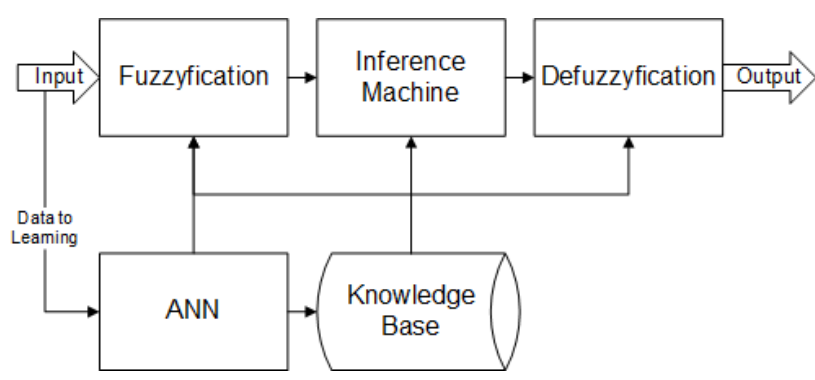

Gambar. 7 Proses ANFIS

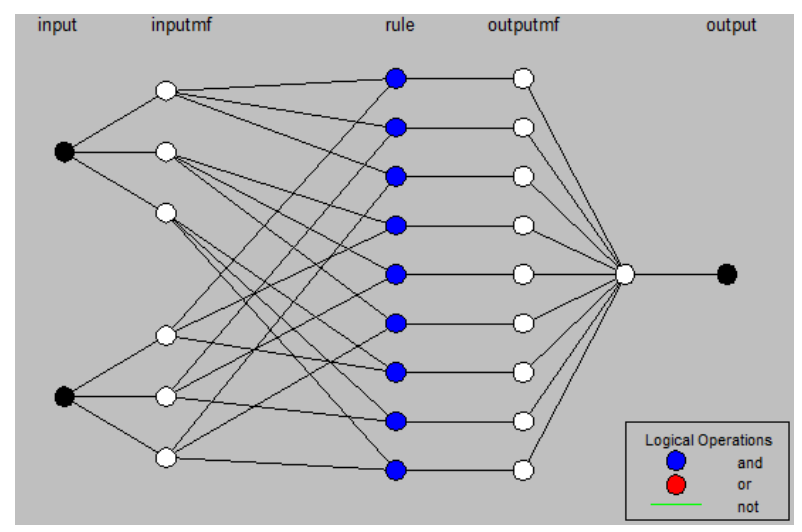

Gambar. 8 Arsitektur jaringan ANN pada ANFIS untuk E2

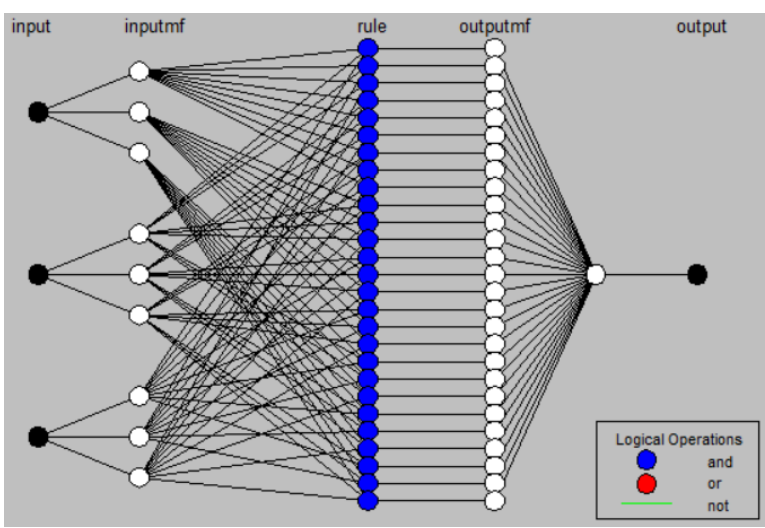

Gambar 9. Arsitektur Jaringan ANN pada ANFIS untuk E3
Adapun parameter-parameter ANFIS yang diuji coba ditunjukkan pada Tabel IV berikut ini, di mana fungsi keanggotaan ANFIS untuk tiap-tiap variabel input pada eksperimen E2 ditunjukkan pada Gambar 10 dan eksperiemen E3 ditunjukkan pada Gambar 11.

TABEL IV

PARAMETER ANFIS YANG DIUJI COBA

\begin{tabular}{ll}
\hline Parameter & Value \\
\hline Fungsi Keanggotaan & TriMf, TrapMf, GaussMf \\
Jumlah Keanggotaan & 3 s/d 6 \\
Epoch & $>=50$ \\
Target Error & $1,00 \mathrm{E}-06$ \\
\hline
\end{tabular}
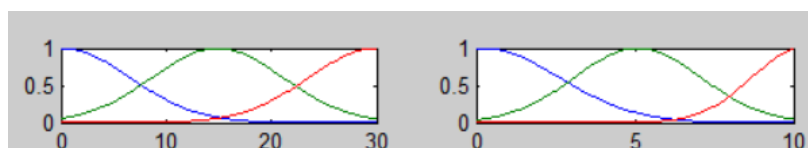

QQ1 (Queues Quantity)

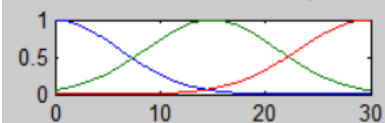

QQ2 (Queues Quantity)
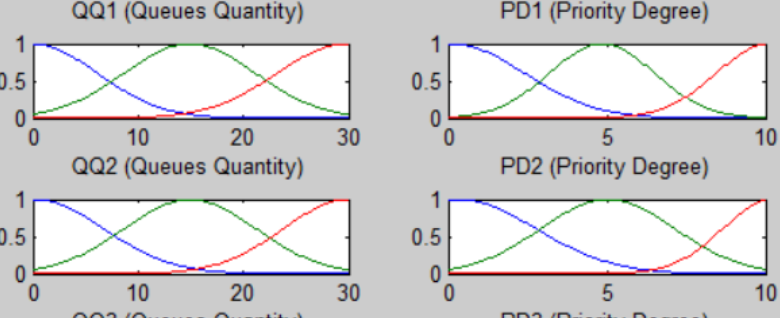

PD2 (Priority Degree)

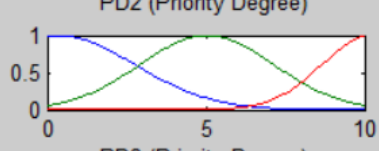

QQ3 (Queues Quantity)

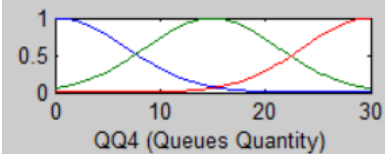

PD3 (Priority Degree)

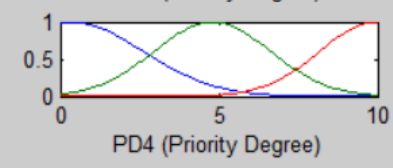

Gambar. 10 Fungsi keanggotaan variabel QQ dan PD untuk E2

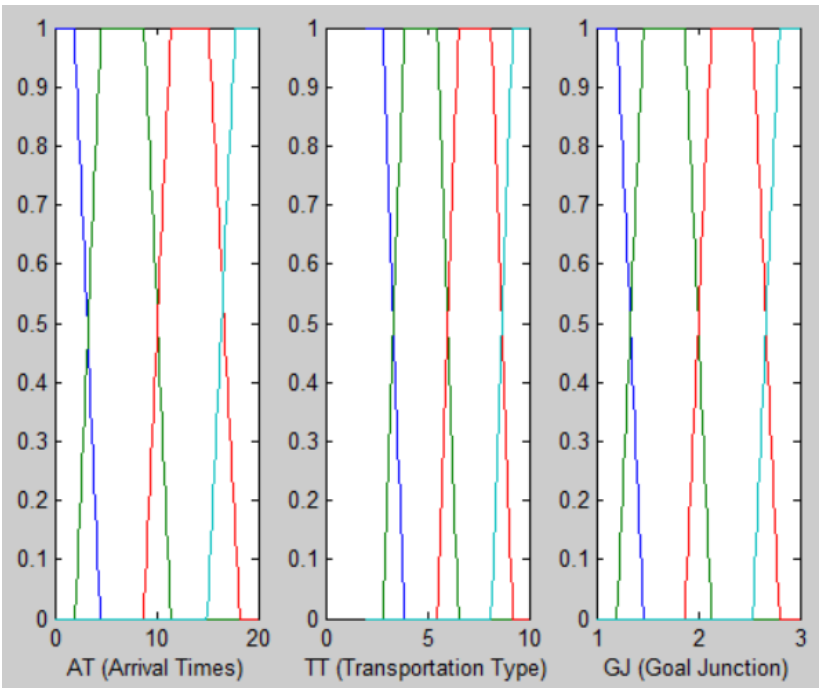

Gambar. 11 Fungsi keanggotaan variabel AT, TT, dan GJ untuk E3

\section{AWT dan RMSE}

Model/metode yang diusulkan untuk pengendalian lampu lalu lintas cerdas dievaluasi berdasarkan Average Waiting Times (AWT) yang mampu direduksi dan error estimation yang diperoleh menggunakan pendekatan Root Mean Squared Error (RMSE) (2). 


$$
\text { RMSE }=\sqrt{\frac{\sum_{\mathrm{i}=1}^{\mathrm{n}}\left(\mathrm{x}_{\mathrm{i}}-\mathrm{x}_{\mathrm{i}}^{\prime}\right)^{2}}{\mathrm{n}}}
$$

Dimana $n$ adalah banyaknya data, $x_{i}$ adalah output aktual data $k e-i$, dan $x_{i}^{\prime}$ adalah output yang diprediksi ANFIS.

\section{HASIL PENELITIAN}

\section{A. Model FIS untuk Penentuan PD pada Dataset DI (E1)}

Eksperimen E1 menggunakan metode FIS untuk penentuan PD pada dataset D1 dengan inputan QQ dan WT di tiap-tiap ruas (Tabel V). Output FIS (PD) pada eksperimen E1 ini akan digunakan sebagai salah satu inputan pada eksperimen E2 menggunakan ANFIS untuk menentukan nilai WT, di mana nilai WT sebelumnya (WT aktual) berfungsi sebagai inputan. Eksperimen E1 (Model FIS untuk penentuan PD pada dataset D1) ini tidak dievaluasi karena hanya berfungsi untuk menentukan nilai PD saja.

TABEL V

DATASET D1 UNTUK PENENTUAN PD MENGGUNAKAN FIS

\begin{tabular}{rrrrrrrrrrrr}
\hline \multicolumn{1}{c}{ Ruas A } & \multicolumn{1}{c}{ Ruas B } & \multicolumn{1}{c}{ Ruas C } & \multicolumn{1}{c}{ Ruas D } \\
QQ1 WT1 PD1 QQ2 WT2 PD2 QQ3WT3 PD3 QQ4 WT4 PD4 \\
\hline \multicolumn{1}{c}{0} & $?$ & 15 & 20 & $?$ & 16 & 20 & $?$ & 27 & 20 & $?$ \\
17 & 20 & $?$ & 0 & 0 & $?$ & 20 & 40 & $?$ & 29 & 40 & $?$ \\
12 & 40 & $?$ & 17 & 20 & $?$ & 0 & 0 & $?$ & 20 & 60 & $?$ \\
29 & 60 & $?$ & 22 & 40 & $?$ & 24 & 20 & $?$ & 0 & 0 & $?$ \\
0 & 0 & $?$ & 29 & 60 & $?$ & 30 & 40 & $?$ & 30 & 20 & $?$ \\
11 & 20 & $?$ & 0 & 0 & $?$ & 25 & 60 & $?$ & 28 & 40 & $?$ \\
$\ldots$ & $\ldots$ & $\ldots$ & $\ldots$ & $\ldots$ & $\ldots$ & $\ldots$ & $\ldots$ & $\ldots$ & $\ldots$ & $\ldots$ & $\ldots$ \\
7 & 60 & $?$ & 10 & 40 & $?$ & 26 & 20 & $?$ & 0 & 0 & $?$ \\
\hline
\end{tabular}

Fungsi keanggotaan yang digunakan adalah TriMF dengan jumlah keanggotaan untuk setiap variabel $=3$ (secara rinci ditunjukkan pada Gambar 4, Gambar 5, dan Gambar 6) [12]. Knowledge Base terdiri dari 9 rule [12]. Parameter Defuzzification yang digunakan adalah "mom" dengan menggunakan teknik Fuzzy Mamdami agar inputan minimum dapat menghasilkan output minimum pula, begitupun inputan maksimum dapat menghasilkan output maksimum pula. Hasil penentuan PD yang diberikan FIS ditunjukkan pada Tabel VI.

\section{B. Model ANFIS untuk Penentuan WT pada Dataset DI (E2)}

Eksperimen E2 menggunakan metode ANFIS untuk penentuan WT pada dataset D1 yang merupakan hasil eksperimen E1 dengan inputan QQ dan PD (Tabel VI). Fungsi keanggotaan yang diuji coba adalah TriMf, TrapMf, dan Gauss $M f$ dengan jumlah keanggotaan yang diuji coba untuk setiap variabel input $=3,4,5$, dan 6. Sedangkan parameter epoch pada ANN yang diuji coba >= 50 dengan error target $=1,00 \mathrm{E}-6$.
TABEL VI

DATASET D1 UNTUK PENENTUAN WT MENGGUNAKAN ANFIS

\begin{tabular}{|c|c|c|c|c|c|c|c|c|c|c|c|}
\hline & 1as & & & uas 1 & & & das C & & & Ias I & \\
\hline QQ1 & & T1 & $\mathbf{Q}$ & PD & $\mathbf{T}$ & $\mathbf{Q}$ & PD & $\mathbf{T}$ & O & ?I & TT4 \\
\hline 0 & 0,0 & 0 & 15 & 3,3 & 20 & 16 & 3,3 & 20 & 27 & 6,7 & 20 \\
\hline 17 & 3,3 & 20 & 0 & 0,0 & 0 & 20 & 6,7 & 40 & 29 & 8,3 & 40 \\
\hline 12 & 6,7 & 40 & 17 & 3,3 & 20 & 0 & 0,0 & 0 & 20 & 8,3 & 60 \\
\hline 29 & 9,8 & 60 & 22 & 8,3 & 40 & 24 & 6,7 & 20 & 0 & 0,0 & 0 \\
\hline 0 & 0,0 & 0 & 29 & 9,8 & 60 & 30 & 8,3 & 40 & 30 & 6,7 & 20 \\
\hline 11 & 3,3 & 20 & 0 & 0,0 & 0 & 25 & 9,2 & 60 & 28 & 8,3 & 40 \\
\hline$\ldots$ & $\ldots$ & $\ldots$ & $\ldots$ & .. & $\ldots$ & $\ldots$ & .. & $\ldots$ & $\ldots$ & . & . \\
\hline 7 & 5,0 & 60 & 10 & 5,0 & 40 & 26 & 6,7 & 20 & 0 & 0,0 & 0 \\
\hline
\end{tabular}

Berdasarkan hasil evaluasi, kinerja terbaik ANFIS dalam mereduksi AWT diperoleh ketika menggunakan fungsi keanggotaan Gauss $M f$ dan jumlah keanggotaan $=3$, di mana AWT rata-rata yang mampu direduksi sebesar 3,4071E-5 detik dengan RMSE rata-rata sebesar 2,7156. AWT yang mampu direduksi pada tiap-tiap ruas menunjukkan bahwa semakin rendah jumlah keanggotaan yang digunakan, maka semakin tinggi pula AWT yang mampu direduksi. Begitupun RMSE, semakin rendah jumlah keanggotaan yang digunakan, maka semakin rendah pula RMSE yang diperoleh. Secara rinci, hasil evaluasi eksperimen E2 ditunjukkan pada Tabel VII, Tabel VIII, Gambar 12, Gambar 13, dan Gambar 14 berikut ini.

TABEL VII

AWT REDUCTION ANFIS PADA E2

\begin{tabular}{|c|c|c|c|c|c|}
\hline & & Ruas A & Ruas B & Ruas C & Ruas D \\
\hline \multirow{4}{*}{$\sum^{E}$} & 3 & $-1.1926 \mathrm{E}-05$ & $1.2199 \mathrm{E}-05$ & $2.0721 \mathrm{E}-05$ & $1.6765 \mathrm{E}-05$ \\
\hline & 4 & $-5.0202 \mathrm{E}-06$ & $-1.2156 \mathrm{E}-05$ & $-1.9776 \mathrm{E}-05$ & $1.3815 \mathrm{E}-05$ \\
\hline & 5 & $6.6042 \mathrm{E}-06$ & $-2.8017 \mathrm{E}-06$ & $-1.0739 \mathrm{E}-06$ & 2.9304E-06 \\
\hline & 6 & $-9.2953 \mathrm{E}-07$ & 2.8709E-06 & 8.1197E-06 & $1.0034 \mathrm{E}-05$ \\
\hline \multirow{4}{*}{ 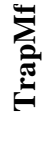 } & 3 & $9.9513 \mathrm{E}-06$ & $1.1344 \mathrm{E}-05$ & $3.2257 \mathrm{E}-06$ & $1.0981 \mathrm{E}-05$ \\
\hline & 4 & $1.5184 \mathrm{E}-05$ & 4.6148E-06 & 3.3207E-06 & $1.1225 \mathrm{E}-06$ \\
\hline & 5 & $-1.8085 \mathrm{E}-05$ & $-5.8463 \mathrm{E}-06$ & $-1.6335 \mathrm{E}-05$ & $-3.8035 \mathrm{E}-06$ \\
\hline & 6 & -8.4041E-06 & -7.4619E-06 & $1.3838 \mathrm{E}-06$ & $-1.1308 \mathrm{E}-05$ \\
\hline \multirow{4}{*}{ 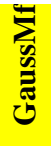 } & 3 & $2.9984 \mathrm{E}-05$ & $1.4792 \mathrm{E}-05$ & 3.3454E-05 & $5.8056 \mathrm{E}-05$ \\
\hline & 4 & $-2.7033 \mathrm{E}-05$ & $-3.8208 \mathrm{E}-05$ & $-2.2768 \mathrm{E}-05$ & $-4.1005 \mathrm{E}-05$ \\
\hline & 5 & $-1.0985 \mathrm{E}-05$ & $7.4600 \mathrm{E}-06$ & $-7.4704 \mathrm{E}-06$ & $-1.3230 \mathrm{E}-05$ \\
\hline & 6 & $-7.8568 \mathrm{E}-06$ & $-1.5724 \mathrm{E}-05$ & $-1.7320 \mathrm{E}-05$ & $-4.6249 \mathrm{E}-06$ \\
\hline
\end{tabular}

\begin{tabular}{|c|c|c|c|c|c|}
\hline & & Ruas A & Ruas B & Ruas C & Ruas D \\
\hline \multirow{4}{*}{$\sum_{E}$} & 3 & 3.0936 & 3.1797 & 3.0513 & 3.6101 \\
\hline & 4 & 1.2213 & 1.0266 & 1.1094 & 1.2721 \\
\hline & 5 & 1.3465 & 1.2721 & 1.4672 & 1.9764 \\
\hline & 6 & 1.2118 & 0.8995 & 0.7947 & 1.4911 \\
\hline \multirow{4}{*}{ 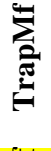 } & 3 & 2.3561 & 2.1042 & 2.5186 & 2.6896 \\
\hline & 4 & 2.1731 & 2.2583 & 2.4523 & 2.9395 \\
\hline & 5 & 1.6028 & 1.2229 & 1.6738 & 1.5504 \\
\hline & 6 & 0.7976 & 0.6788 & 0.8191 & 1.0977 \\
\hline \multirow{4}{*}{ 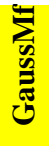 } & 3 & 2.5132 & 2.4424 & 2.9099 & 2.9967 \\
\hline & 4 & 1.7153 & 1.6297 & 1.9149 & 2.2943 \\
\hline & 5 & 1.4222 & 0.9442 & 1.1721 & 1.4627 \\
\hline & 6 & 1.0418 & 1.0123 & 0.9325 & 1.1197 \\
\hline
\end{tabular}




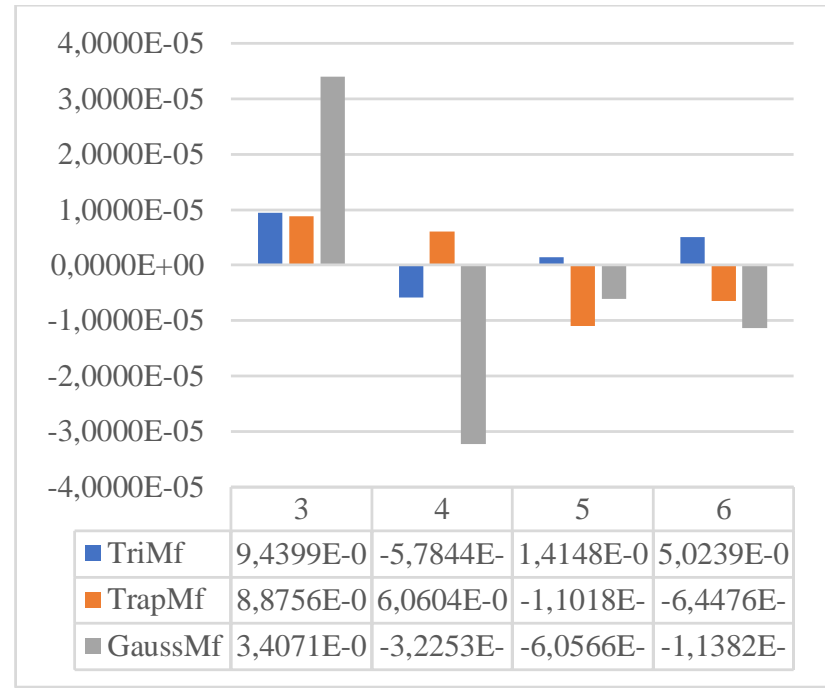

Gambar. 12 AWT reduction rata-rata ANFIS pada E2

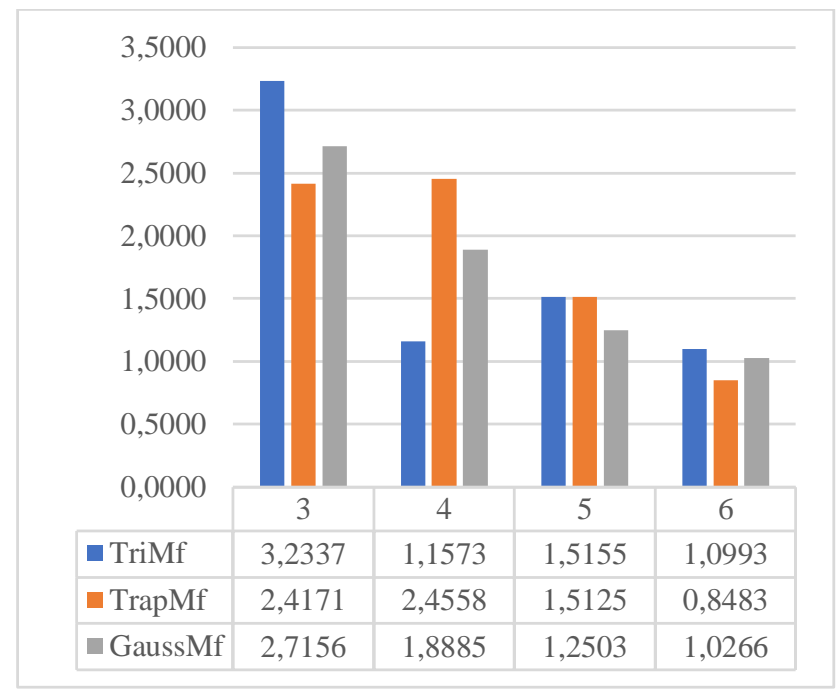

Gambar. 13 RMSE rata-rata ANFIS pada E2

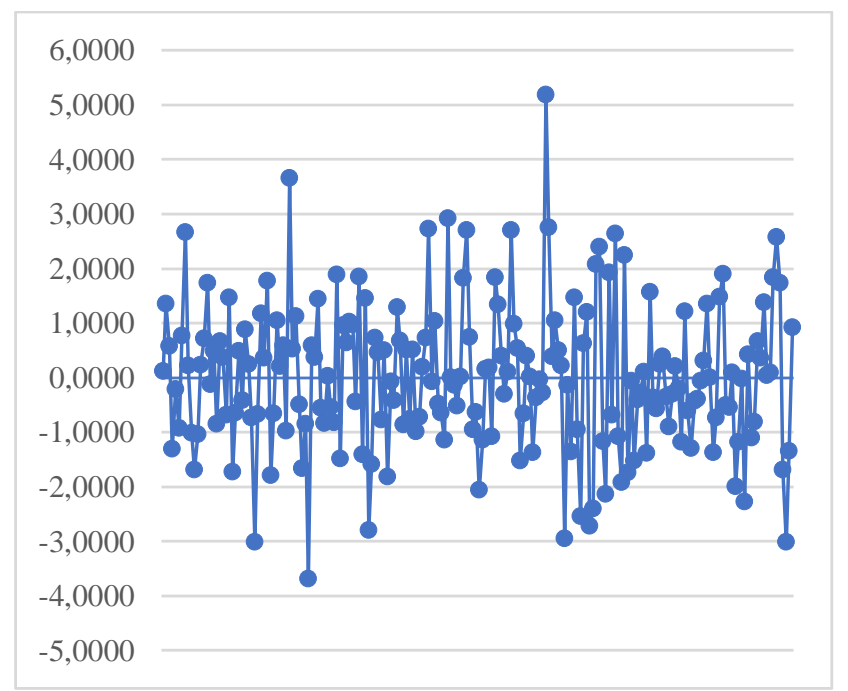

Gambar. 14 AWT reduction rata-rata ANFIS pada E2 (3 GaussMf)

\section{Model ANFIS untuk Penentuan WT pada Dataset D2 (E3)}

Eksperimen E3 menggunakan metode ANFIS untuk penentuan WT pada dataset D2 dengan inputan AT, TT, dan GJ (Tabel IX). Fungsi keanggotaan yang diuji coba adalah TriMf, TrapMf, dan GaussMf dengan jumlah keanggotaan yang diuji coba untuk setiap variabel input $=$ $3,4,5$, dan 6. Sedangkan parameter epoch pada ANN yang diuji coba $>=50$ dengan error target $=1,00 \mathrm{E}-6$.

TABEL IX

DATASET D2 UNTUK PENENTUAN WT MENGGUNAKAN ANFIS

\begin{tabular}{lrrrr}
\hline No & AT & TT & GJ & WT \\
\hline 1 & 0 & 4 & 3 & 80 \\
2 & 1 & 4 & 2 & 90 \\
3 & 2 & 4 & 1 & 40 \\
4 & 3 & 4 & 1 & 45 \\
5 & 4 & 2 & 2 & 85 \\
6 & 5 & 2 & 1 & 25 \\
$\ldots$ & $\ldots$ & $\ldots$ & $\ldots$ & $\ldots$ \\
231 & 20 & 4 & 1 & 55 \\
\hline
\end{tabular}

Berdasarkan hasil evaluasi, kinerja terbaik ANFIS dalam mereduksi AWT diperoleh ketika menggunakan fungsi keanggotaan TrapMf dan jumlah keanggotaan $=4$, di mana AWT yang mampu direduksi sebesar 0,0779 detik dengan RMSE sebesar 19,7646. AWT yang mampu direduksi menunjukkan bahwa fungsi keanggotaan TrapMf selalu memberikan hasil yang lebih baik pada setiap jumlah keanggotaan yang diuji coba, kecuali pada jumlah keanggotaan $=3$. Sedangkan RMSE yang dihasilkan menunjukkan bahwa semakin rendah jumlah keanggotaan, maka semakin rendah pula nilai RMSE, baik pada fungsi keanggotaan TriMf, TrapMf, maupun GaussMf. Secara rinci, hasil evaluasi eksperimen E3 ditunjukkan pada Gambar 15, Gambar 16, Gambar 17, dan Gambar 18.

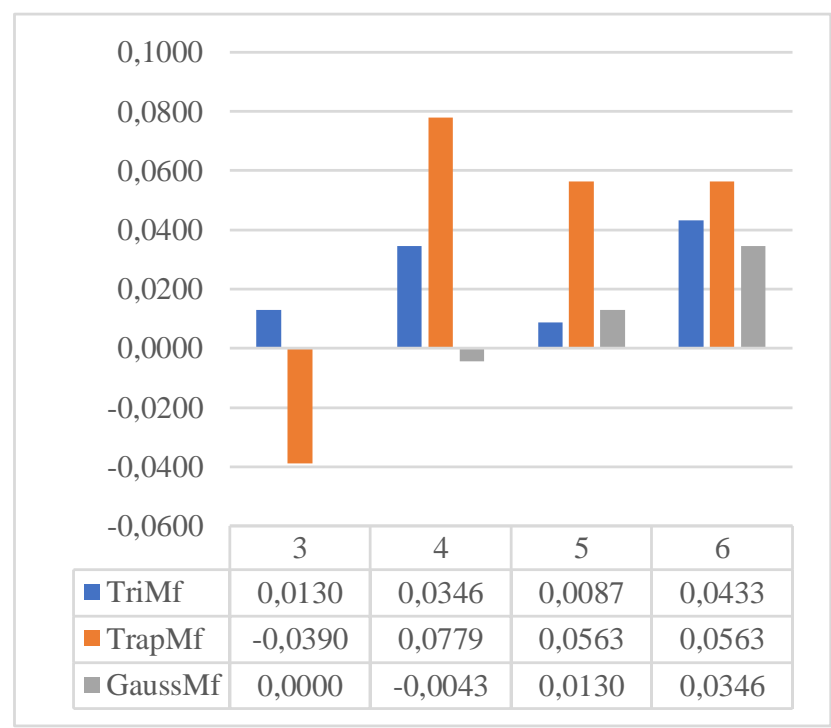

Gambar. 15 AWT reduction ANFIS pada E3 


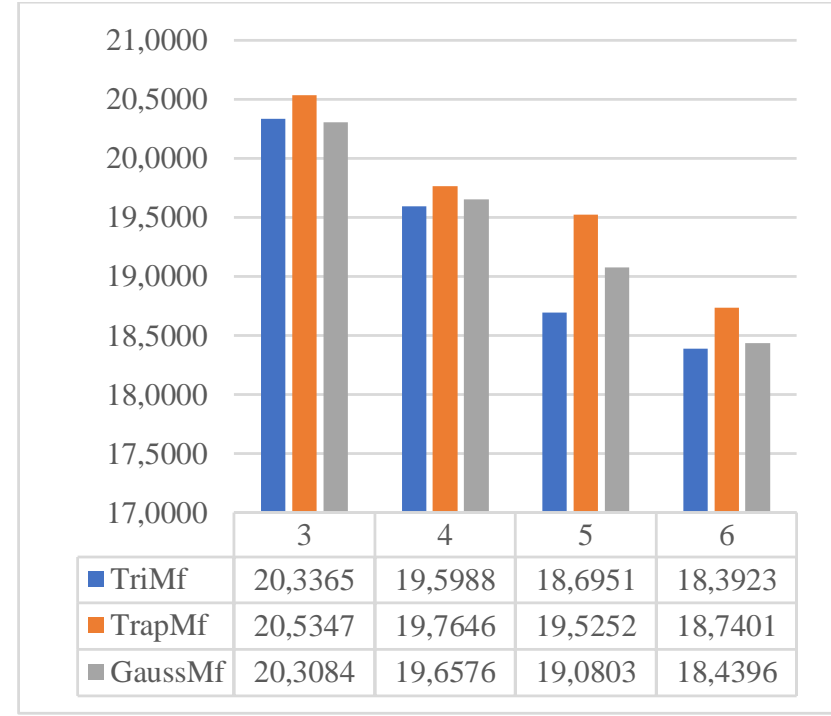

Gambar. 16 RMSE ANFIS pada E3

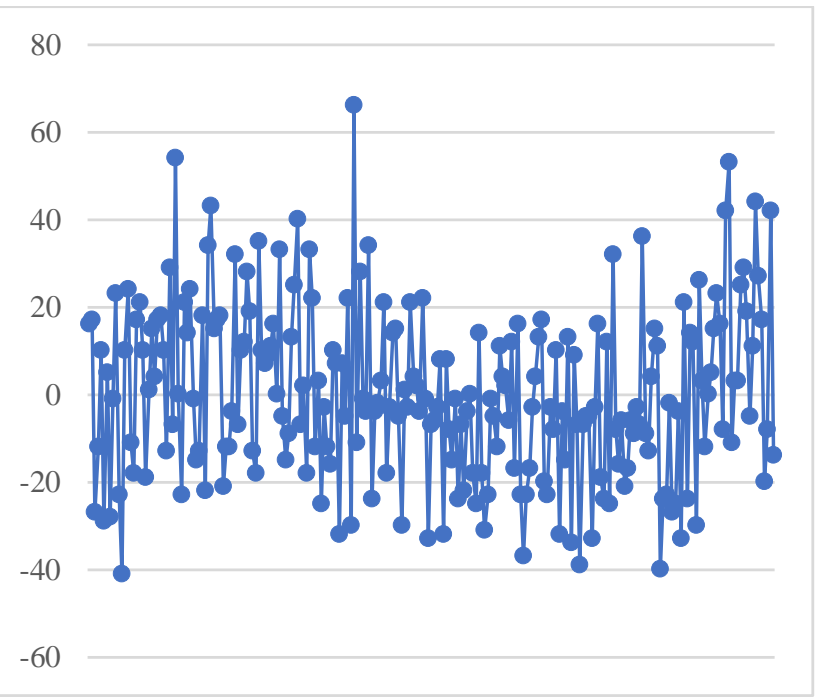

Gambar. 17 WT reduction ANFIS pada E3 (4 TrapMf)

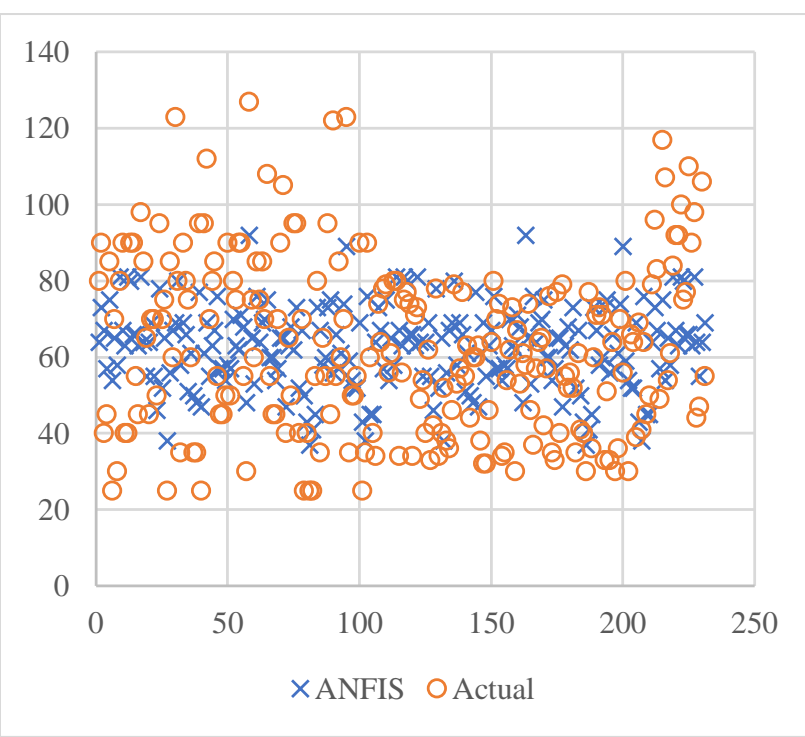

Gambar. 18 Output WT aktual vs ANFIS pada E3 (4 TrapMf)
Berdasarkan seluruh evaluasi dari model-model yang diuji coba, model ANFIS untuk pengendalian lampu lalu lintas cerdas secara dinamis di persimpangan empat ruas yang kompleks dengan menggunakan variabel AT, TT, dan GT (eksperimen E3) lebih baik dalam mereduksi AWT daripada menggunakan variabel QQ dan PD (eksperimen E2), yaitu selisih 0,077888 detik. Namun sebaliknya untuk error estimation RMSE, ANFIS pada eksperimen E2 menunjukkan kinerja yang lebih baik daripada ANFIS pada eksperimen E3, yaitu dengan selisih 17,04906. Kinerja AWT reduction lebih dipertimbangkan daripada kinerja error estimation karena dalam penelitian ini, error estimation yang diperoleh berdasarkan data aktual yang dikumpulkan di lokasi penelitian yang validitasnya belum teruji dengan baik. Sedangkan AWT yang mampu direduksi mengindikasikan bahwa metode yang diusulkan ini akan mampu mereduksi kemacetan arus lalu lintas di persimpangan tersebut. Dengan demikian, model ANFIS pada eksperimen E3 dapat digunakan untuk pengendalian lampu lalu lintas cerdas secara dinamis pada persimpangan tersebut.

\section{Simulasi}

Prosedur terakhir yaitu simulasi pengendalian lampu lalu lintas cerdas secara dinamis di persimpangan empat ruas yang kompleks menggunakan metode ANFIS yang ditunjukkan pada Gambar 19 (E4). Simulasi dilakukan dengan mengikuti model eksperimen E1 dengan penjelasan simulasi ini adalah sebagai berikut:

1. Lampu hijau menyala pada ruas yang memperoleh PD tertinggi berdasarkan inputan QQ dan WT dari setiap ruas dengan durasi lampu hijau berdasarkan nilai GT;

2. Selanjutnya waktu lampu hijau dihitung mundur, saat mencapai 0, maka ANFIS kembali bekerja untuk memberikan output PD berdasarkan dataset D1;

3. Diasumsikan bahwa setiap periode lampu hijau, 1 kendaraan masuk pada tiap-tiap ruas $(\mathrm{QQ}=\mathrm{QQ}+1)$, kecuali pada ruas lampu hijau yang baru berakhir menjadi lampu merah $(\mathrm{QQ}=0)$; dan

4. Diasumsikan pula bahwa setiap periode lampu hijau, WT suatu ruas bertambah berdasarkan durasi lampu hijau sebelumnya (WT = WT + GT sebelumnya pada ruas lampu hijau), kecuali pada ruas lampu hijau yang baru berakhir menjadi lampu merah $(\mathrm{WT}=0)$.

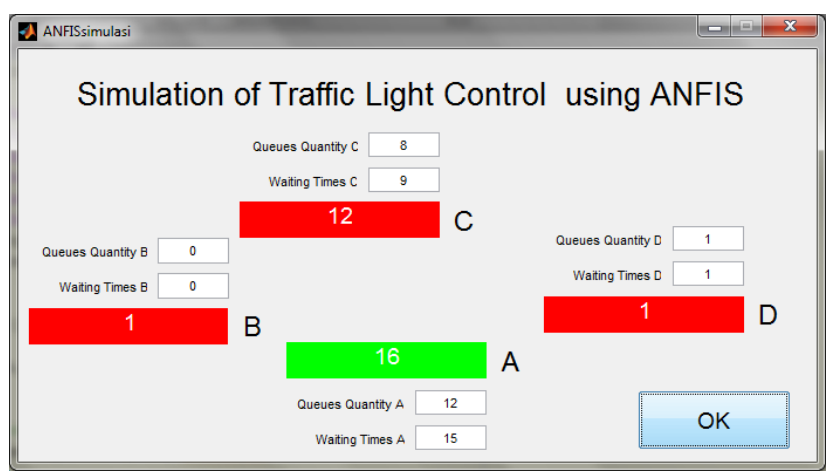

Gambar. 19 Simulasi 


\section{KESIMPULAN}

Berdasarkan hasil penelitian yang diperoleh, maka dapat disimpulkan bahwa:

1. Penerapan ANFIS (3 Gauss $M f$ ) untuk pengendalian lampu lalu lintas cerdas/dinamis di persimpangan empat ruas yang kompleks mampu mereduksi Average Waiting Times (AWT) rata-rata sebesar 3,4071E-05 detik dengan 2,7156 RMSE rata-rata, menggunakan variabel Queues Quantity (QQ) dan Priority Degree (PD);

2. Sedangkan jika menggunakan variabel Arrival Times (AT), Transportation Type (TT), dan Goal Junction (GJ), ANFIS (4 TrapMf) mampu mereduksi AWT sebesar 0,0779 detik dengan 19,7646 RMSE.

Dengan demikian, model ANFIS (4 TrapMf) dengan menggunakan variabel AT, TT, dan GJ yang lebih mampu mereduksi AWT dapat diterapkan untuk pengendalian lampu lalu lintas cerdas/dinamis di persimpangan empat ruas yang kompleks. Selain itu, hasil ini juga mengindikasikan bahwa model ANFIS dengan inputan per kendaraan lebih direkomendasikan daripada inputan per ruas (akumulasi kendaraan per ruas). Oleh karena itu, penelitian ke depannya dapat melakukan simulasi terhadap model ANFIS (4 TrapMf) ini dengan variabel output yang berbeda yang dapat digunakan untuk durasi lampu hijau.

Untuk lebih menguji kinerja dari metode yang diusulkan ini, maka penerapannya pada berbagai lokasi yang berbeda dapat pula diuji coba pada penelitian-penelitian selanjutnya. Begitupun data yang lebih valid, lebih banyak, lebih bersifat publik, dan lebih bersih dari noise dibutuhkan pula.

\section{UCAPAN TERIMA KASIH}

Penelitian ini didukung dan didanai oleh: (1) Direktorat Riset dan Pengabdian Masyarakat; (2) Kementerian Riset dan Pendidikan Tinggi Republik Indonesia.

\section{REFERENSI}

[1] D. L. Borg and K. Scerria, "Constrained Dynamic Control of Traffic Junctions," in Procedia Computer Science, 2014, vol. 32, pp. 293-300.

[2] T. Brys, T. T. Pham, and M. E. Taylor, "Distributed learning and multi-objectivity in traffic light control," Conn. Sci., vol. 26, no. 1, pp. 65-83, 2014.

[3] K. Nellore and G. P. Hancke, "A Survey on Urban Traffic Management System Using Wireless Sensor Networks," Sensors, vol. 16, no. 2, pp. 1-25, 2016.

[4] L. Qi, M. Zhou, and W. Luan, "A Two-level Traffic Light Contro Strategy for Preventing Incident-Based Urban Traffic Congestion," IEEE Trans. Intell. Transp. Syst., vol. 19, no. 1, pp. 13-24, 2016.

[5] P. Mittal and Y. Singh, "Development of Intelligent Transportation System for Improving Average Moving and Waiting Time with Artificial Intelligence," Indian J. Sci. Technol., vol. 9, no. 3, pp. 17, 2016.

[6] B. S. Putra, R. S. Wahono, and R. I. Akbar, "Simulasi Penerapan ANFIS pada Sistem Lampu Lalu Lintas Enam Ruas," Kursor, vol. 6, no. 2, pp. 77-82, 2011.

[7] S. Kwatirayo, J. Almhana, and Z. Liu, "Adaptive Traffic Light Control Using VANET: A Case Study," in 2013 9th International Wireless Communications and Mobile Computing Conference (IWCMC), 2013, pp. 752-757.

[8] S. Mehan and V. Sharma, "Development of Traffic Light Control System Based on Fuzzy Logic," in Proceedings of the International Conference on Advances in Computing and Artificial Intelligence -
ACAI' '11, 2011, pp. 162-165.

[9] Z. Cao, S. Jiang, J. Zhang, and H. Guo, "A Unified Framework for Vehicle Rerouting and Traffic Light Control to Reduce Traffic Congestion," IEEE Trans. Intell. Transp. Syst., vol. 18, no. 7, pp. 1958-1973, 2016.

[10] A. L. C. Bazzan and F. Klugl, "A review on agent-based technology for traffic and transportation," Knowl. Eng. Rev., vol. 29, no. 3, pp. 375-403, 2014

[11] K.-L. A. Yau, J. Qadir, H. L. Khoo, M. H. Ling, and P. Komisarczuk, "A Survey on Reinforcement Learning Models and Algorithms for Traffic Signal Control," ACM Comput. Surv., vol. 50, no. 3, pp. 1-38, 2017.

[12] R. Hawi, G. Okeyo, and M. Kimwele, "Smart Traffic Light Control using Fuzzy Logic and Wireless Sensor Network," in 2017 Computing Conference, 2017, pp. 450-460.

[13] M. Patel and N. Ranganathan, "IDUTC : An Intelligent DecisionMaking System for Urban Traffic-Control Applications," IEEE Trans. Veh. Technol., vol. 50, no. 3, pp. 816-829, 2001.

[14] D. T. Larose and C. D. Larose, Discovering Knowledge in Data: An Introduction to Data Mining, 2nd ed. Wiley, 2014.

[15] I. H. Witten, E. Frank, and M. A. Hall, Data Mining: Practical Machine Learning Tools and Techniques, 3rd ed. Elsevier, 2011.

[16] J. Han, M. Kamber, and J. Pei, Data Mining: Concepts and Techniques, 3rd ed. Elsevier, 2012.

[17] J. Cheng, W. Wu, J. Cao, and K. Li, "Fuzzy Group-based Intersection Control via Vehicular Networks for Smart Transportations," IEEE Trans. Ind. Informatics, vol. 13, no. 2, pp. 751-758, 2017.

[18] A. Sharma, R. Vijay, G. I. Bodhe, and L. G. Malik, "An adaptive neuro-fuzzy interface system model for traffic classification and noise prediction," Soft Comput., vol. 22, no. 6, pp. 1891-1902, 2016.

[19] M. Wiering, J. van Veenen, J. Vreeken, and A. Koopman, "Intelligent Traffic Light Control," Transp. Res., 2004.

[20] D. Srinivasan, M. C. Choy, and R. L. Cheu, "Neural Networks for Real-Time Traffic Signal Control," IEEE Trans. Intell. Transp. Syst., vol. 7, no. 3, pp. 261-272, 2006.

[21] S. Islam, M. S. Bhuyan, A. Azim, I. K. Teng, and M. Othman, "Hardware Implementation of Traffic Controller using Fuzzy Expert System," in International Symposium on Evolving Fuzzy Systems, 2006, pp. 325-330.

[22] M. Tubaishat, Y. Shang, and H. Shi, "Adaptive Traffic Light Control with Wireless Sensor Networks," in 2007 4th IEEE Consumer Communications and Networking Conference, 2007, pp. 187-191.

[23] V. Hirankitti, J. Krohkaew, and C. Hogger, "A Multi-Agent Approach for Intelligent Traffic-Light Control," in Proceedings of the Word Congress on Engineering, 2007, vol. 1.

[24] W. Wen, "A dynamic and automatic traffic light control expert system for solving the road congestion problem," Expert Syst. Appl. vol. 34, no. 4, pp. 2370-2381, 2008.

[25] K. Y. R. Cheng, C. H. L. Lee, and A. Liu, "Designing Intelligent Agents for Traffic Delay Compensation," J. Integr. Syst. Des. Process Sci., vol. 12, no. 4, pp. 15-26, 2008

[26] R. Taufik, Supriyono, and Sukarman, "Rancang Bangun Simulator Kendali Lampu Lalu Lintas dengan Logika Fuzzy Berbasis Mikrokontroler," in Seminar Nasional IV SDM Teknologi Nuklir, 2008, pp. 459-466.

[27] H. Lin, K. M. Aye, H. M. Tun, Theingi, and Z. M. Naing, "Design and Construction of Intelligent Traffic Light Control System Using Fuzzy Logic," in International Conference on Power Control and Optimization, Innovation in Power Control for Optimal Industry, 2008, pp. 237-239.

[28] S. Mehta, "Fuzzy Control System for Controlling Traffic Lights," in International Multi Conference of Engineers and Computer Scientist, 2008, pp. 105-108.

[29] L. Dimitriou, T. Tsekeris, and A. Stathopoulos, "Adaptive hybrid fuzzy rule-based system approach for modeling and predicting urban traffic flow," Transp. Res. Part C Emerg. Technol., vol. 16, no. 5, pp. 554-573, 2008 .

[30] R. Wahyu and L. Afriyanti, “Aplikasi Fuzzy Inference System (FIS) Metode Tsukamoto pada Simulasi Traffic Light Menggunakan Java," in Seminar Nasional Aplikasi teknologi Informasi, 2009, pp. 
104-107.

[31] T. Le and C. Cai, "A New Feature For Approximate Dynamic Programming Traffic Light Controller," in Proceedings of the Third International Workshop on Computational Transportation Science - IWCTS '10, 2010, pp. 29-34.

[32] E. Azimirad, N. Pariz, and M. B. N. Sistani, "A Novel Fuzzy Model and Control of Single Intersection at Urban Traffic Network," IEEE Syst. J., vol. 4, no. 1, pp. 107-111, 2010.

[33] C. Karakuzu and O. Demirci, "Fuzzy logic based smart traffic light simulator design and hardware implementation," Appl. Soft Comput., vol. 10, no. 1, pp. 66-73, 2010.

[34] P. G. Balaji and D. Srinivasan, "Multi-agent system in urban traffic signal control," IEEE Comput. Intell. Mag., vol. 5, no. 4, pp. 43 51,2010

[35] M. Fiosins, J. Fiosina, J. P. Müller, and J. Gormer, “Agent-Based Integrated Decision Making for Autonomous Vehicles in Urban Traffic," Adv. Pract. Appl. Agents Multiagent Syst., pp. 173-178, 2011.

[36] S. Faye, C. Chaudet, and I. Demeure, "A Distributed Algorithm for Multiple Intersections Adaptive Traffic Lights Control using a Wireless Sensor Networks," in Proceedings of the first workshop on Urban networking - Urbane '12, 2012, pp. 13-18.

[37] D. McKenney and T. White, "Distributed and adaptive traffic signal control within a realistic traffic simulation," Eng. Appl. Artif. Intell., vol. 26, no. 1, pp. 574-583, 2013.

[38] S. G. Rabiha and S. Santosa, "Prediksi Data Arus Lalu Lintas Jangka Pendek Menggunakan Optimasi Neural Network Berbasis Genetik Algorithm," J. Teknol. Inf., vol. 9, no. 2, pp. 54-61, 2013.

[39] J. Kianfar and P. Edara, "A Data Mining Approach to Creating Fundamental Traffic Flow Diagram," in Procedia Social and Behavioral Sciences, 2013, vol. 104, pp. 430-439.

[40] J. Garcia-Nieto, A. C. Olivera, and E. Alba, "Optimal Cycle Program of Traffic Lights With Particle Swarm Optimization," IEEE Trans. Evol. Comput., vol. 17, no. 6, pp. 823-839, 2013.

[41] S. Araghi, A. Khosravi, M. Johnstone, and D. Creighton, "Intelligent Traffic Light Control of Isolated Intersections Using Machine Learning Methods," 2013 IEEE Int. Conf. Syst. Man, Cybern., pp. 3621-3626, 2013.

[42] M. B. W. de Oliveira and A. de A. Neto, "Optimization of Traffic Lights Timing based on Artificial Neural Networks," in 17th International IEEE Conference on Intelligent Transportation Systems (ITSC), 2014, pp. 1921-1922.

[43] M. B. Younes and A. Boukerche, "Intelligent Traffic Light Controlling Algorithms Using Vehicular Networks," IEEE Trans. Veh. Technol., vol. 65, no. 8, pp. 5887-5899, 2015.

[44] M. Collotta, L. Lo Bello, and G. Pau, "A Novel Approach for dynamic traffic lights management based on Wireless Sensor Networks and Multiple Fuzzy Logic Controllers," Expert Syst. Appl., vol. 42, no. 13, pp. 5403-5415, 2015.

[45] M. K. Abbas, M. N. Karsiti, M. Napiah, B. B. Samir, and M. AlJemali, "High accuracy traffic light controller for increasing the given green time utilization," Comput. Electr. Eng., vol. 41, pp. 4051,2015 .

[46] A. Kridanto and J. L. Buliali, "Metode Hibrida FCM dan PSO-SVR untuk Prediksi Data Arus Lalu Lintas," J. Tek. Inform. dan Sist. Inf., vol. 1, no. 3, pp. 302-311, 2015.

[47] N. R. Yusupbekov, A. R. Marakhimov, H. Z. Igamberdiev, and S. $\mathrm{X}$. Umarov, "Application of soft-computing technologies to the traffic control system design problems," in Procedia Computer Science, 2016, vol. 102, pp. 540-546.

[48] N. Nower and S. Hossan, "Efficient Dynamic Traffic Light Control for ITS," in Proceedings of the Second International Conference on Internet of things, Data and Cloud Computing - ICC '17, 2017.

[49] R. H. Abiyev, M. Ma'aitah, and B. Sonyel, "Fuzzy Logic Traffic Lights Control (FLTLC)," in Proceedings of the 2017 9th International Conference on Education Technology and Computer - ICETC 2017, 2017, pp. 233-238.

[50] J. Jin and X. Ma, "A Decentralized Traffic Light Control System Based on Adaptive Learning," IFAC-PapersOnLine, vol. 50, no. 1 pp. 5301-5306, 2017.

[51] V. Gupta and R. Kumar, "Intelligent Traffic Light Control for Congestion Management for Smart City Development," in 2017 IEEE Region 10 Symposium (TENSYMP), 2017.
[52] E. Harahap, A. Suryadi, Ridwan, D. Darmawan, and R. Ceha, "Efektifitas Load Balancing Dalam Mengatasi Kemacetan Lalu Lintas," J. Mat., vol. 16, no. 2, pp. 1-7, 2017.

[53] J. Liu et al., "Secure intelligent traffic light control using fog computing," Futur. Gener. Comput. Syst., vol. 78, no. 2, pp. 817 824, 2017.

[54] Indrabayu, Y. Lesmana, A. A. Ilham, I. Nurtanio, and S. Hamid, "An Intelligent Traffic Light System for Reducing Number of Queuing Cars in Complex Road Junction," ICIC Express Lett. Part B Appl., vol. 8, no. 6, pp. 999-1006, 2017.

[55] H. Wei, G. Zheng, H. Yao, and Z. Li, "IntelliLight: A Reinforcement Learning Approach for Intelligent Traffic Light Control," in Proceedings of the 24th ACM SIGKDD International Conference on Knowledge Discovery \& Data Mining - KDD '18, 2018, pp. 2496-2505.

[56] P. Ayuba, B. Zachariah, and L. P. Damut, "Modification of Fuzzy Logic Rule Base in The Optimization of Traffic Light Contorl System," Sci. Word J., vol. 13, no. 2, pp. 6-11, 2018.

[57] W. Chen et al., "A novel fuzzy deep-learning approach to traffic flow prediction with uncertain spatial-temporal data features," Futur. Gener. Comput. Syst., vol. 89, pp. 78-88, 2018.

[58] J. Jin and X. Ma, "Hierarchical multi-agent control of traffic lights based on collective learning," Eng. Appl. Artif. Intell., vol. 68, pp. 236-248, 2018

[59] T. Sutojo, E. Mulyanto, and V. Suhartono, Kecerdasan Buatan. Yogyakarta, Indonesia: Andi Offset, 2011. 